\title{
Psychiatry in Venezuela
}

\section{Edgard Belfort ${ }^{1}$ and Javier González ${ }^{2}$}

1Professor of Psychiatry, Venezuela Central University; Chairman, Child and Adolescent Psychiatric Service, Caracas Psychiatric Hospital; Administrative Secretary, Latin American Psychiatric Association (APAL), Av. Libertador. Edif. Majestic No. 148, Caracas 1050, Venezuela, email secretariaapal@cantv.net, belfort.ed@excite.com; Zonal Representative (Northern South America), World Psychiatric Association

${ }^{2}$ Coordinator, Latin American Fellows' Programme; Latin American Psychiatric Association (APAL)

he Bolivarian Republic of Venezuela covers $916445 \mathrm{~km}^{2}$; to the north is the Caribbean Sea, to the south-east the Amazonian region and the plains of Brazil and Colombia, and to the west the Andes and the Colombian Guajira peninsula. Its estimated population (2004) is 25226 million, which is concentrated along the north coastal area, where the population density exceeds 200 inhabitants per $\mathrm{km}^{2}$; most of the territory remains almost inhabited (fewer than 6 inhabitants per $\mathrm{km}^{2}$ ), in particular the border areas. The population is mainly urban: $70 \%$ live in cities with more than 50000 inhabitants.

The annual mean rate of po pulation grow th is $2 \%$, approximately, but this is reducing in line with a progressive reduction in the birth rate (from 27.4 per 1000 inhabitants in 1994 to 22.3 per 1000 in 1998), fertility (3.17 children per 1000 women in 1994 to 2.93 in 1998) and an increase in emigration. The population is predominantly young: $54.4 \%$ are under 25 years of age, while the 25- to 64-year age group represents $41.3 \%$ of the population. Life expectancy is presently estimated at 72.8 years.

The budget assigned to health amounts to $3.9 \%$ of gross domestic product, or U S\$6402 per capita.

Constitutionally, Venezuela is a free and independent republic. It is also a federal state, consisting of 25 states and a capital district; C aracas is the capital city. According to the constitution, the states are autono mous and have political integrity. They are called on, however, to maintain the integrity of the nation and to obey and abide by national law.

\section{Health system}

Civil rights and the state's duties to its citizens set out in the constitution provide the framework for the health system. The state must guarantee opportunities for education and development in an environment of freedom, and must preserve the dignity of its inhabitants, for example. The constitution requires that a technical committee organises the administration of healthcare in Venezuela. This committee has the following duties:

o to study and recommend programmes for the control of important epidemio logical diseases

o to study and develop strategies aimed at eradicating some recurrent (high-prevalence) diseases of social importance
O to suggest action programmes to be developed in the $\mathrm{N}$ ational $\mathrm{Commission}$ for the Zoonoses

o to evaluate, from the epidemiological and malarial point of view, the status of the border states in order to suggest action programmes, considering in particular the health status of indigeno us ethnic groups

o to coordinate the organisation of symposia in environmental hygiene, together with government, municipal authorities, schools and universities, and other civil bodies

o to promote community health

O to take on any other function defined by the Ministry of Health and Social Development (in Spanish MSDS) or its representatives.

There is, however, a need to democratise the health structure, to widen social participation, in order to consolidate the role of the MSDS.

\section{Mental health policies and programmes}

There is a mental health policy, which covers promotion, prevention, treatment and rehabilitation. This policy, based on the 1990 C aracas D eclaration, seeks to integrate psychiatric care within primary care; this involves the decentralisation of services through the provision of day-care hospitals, health centres, prevention programmes and community participation.

There is a national programme of mental health, contained in the $\mathrm{N}$ ation's $\mathrm{N}$ inth Plan (which is a 5-year plan for economic and social development, from which the priorities of the executive power are derived). The public health sector in Venezuela accounts for 214 hospitals (181 general and 33 specialised hospitals) and a network of 4605 ambulato ry clinics for medical care (in 890 urban and 3715 rural centres).

Psychiatric services are provided in both the public and the private sectors. The public system looks after a large portion of the population, but access to psychiatric care is restricted in rural areas. There are few specific services for children and elderly people, even in urban areas.

Psychiatric care tends to be centred on psychiatric hospitals. Patients are referred from general hospitals or other institutions. From the 1960s, 11 rural sanatoriums, which house around 1800 chronic mental patients, were established. The main objective of this project was to create a psychiatric community but
In 1990, the Pan American Health Organization (PAHO/WHO) convened the regional

conference on Restructuring Psychiatric Care in Latin America, held in Caracas, Venezuela. The Declaration of Caracas was adopted in the framework of that conference. The

full text of the declaration is reproduced in Levav et al (1994). 
unfortunately this was never accomplished. Currently these institutes serve the private sector.

There is an overall lack of practical psychiatric care, reflected in an under-provision of institutional structures and poor access to the health system.

\section{Mental health legislation}

Venezuela does not rely on a specific law to regulate all aspects of mental health from a holistic perspective. Issues related to mental health are usually addressed in health codes or general health laws, which set out universal principles. Commissions and technical committees govern the administration of some services and regulate the organisations devoted to mental healthcare.

Resolution number 1223 (15 0 ctober 1992),

Venezuela does not rely on a specific law to regulate all aspects of mental health from a holistic perspective. Issues related to mental health are usually addressed in health codes or general health laws, which set out universal principles. however, does emphasise the responsibility of the MSDS to provide comprehensive medical care for people with a mental illness, oriented towards the patient's full recovery and his/her reintegration in society. The resolution also refers to the principles contained in the $C$ aracas Declaration and asks general hospitals appointed by the MSDS to study and adopt procedures related to the admission of acute psychiatric patients; more specifically, it seeks to guarantee that at least $10 \%$ of beds are available for those with a mental disorder.

There was also a decree in 1992 to regulate the sanato riums. It refers to the humanitarian treatment of patients, in particular their individual freedom and security; it also relates to the admission of patients, technical and professional assistance, specialised medical care, health records and the assumption of responsibilities in the event of injury to patients.

\section{Mental health financing}

There are budget allocations for mental health. The primary so urces of mental health financing, in descending order, are: tax revenue, social insurance, out- ofpocket expenditure by the patient and family, and private health insurance.

\section{Mental health training and facilities}

$D$ isability benefits for persons with mental disorders require a certificate provided by the Venezuelan Institute of Social Security.

Table 1. Central and regional mental health resources
22 states

Psychiatric hospitals

Ambulatory clinics

Day-care hospitals

Psychiatric units in general hospitals

Ambulatory clinics for children and adolescents

Psychiatric units for children and adolescents
Table 2. Numbers of psychiatric beds and professionals

\begin{tabular}{lc}
\hline \multicolumn{1}{c}{ Number per 10000 population } \\
\hline Psychiatric beds & 1.15 \\
Psychiatric beds in mental hospitals & 0.29 \\
Psychiatric beds in general hospitals & 0.15 \\
Psychiatric beds in other settings & 0.76 \\
Psychiatrists & 0.4 \\
\hline
\end{tabular}

Treatment for severe and acute mental disorders is available at primary level in some regions of the country, for example the states of Merida, Tachira and Zulia.

Regular training of primary-care professionals is not carried out in the field of mental health. H owever, there are eight regular training programmes (for a university degree) in general psychiatry and one training programme in child and adolescent psychiatry. These account for $2.82 \%$ of the total resources invested in postgraduate health education programmes.

The establishment and maintenance of mental health services are governed by the MSDS. The reso urces it provides are set out in Tables 1 and 2.

\section{Scientific societies}

The most important of the several psychiatric societies is the Venezuelan Society of Psychiatry, which has approximately 900 members. It is affiliated to the Latin American Psychiatric Asso ciation and the World Psychiatric Association. It organises scientific activities, workshops, symposia, meetings, and a national congress every 3 years.

\section{Mental health research}

The areas of mental health being investigated, in descending order of amount of research activity, are as follows:

O affective disorders (including post-partum depression)

O schizophrenia and other psychotic disorders

o childhood mental and behavioural disorders

0 anxiety diso rders

o drug misuse and dependence

o suicide

o dementia

O learning disabilities

o stress disorders (including post-traumatic stress disorder)

o mental comorbidity of AIDS

O neuropsychiatric disorders

o eating disorders

o epilepsy.

\section{Violence and mental health}

Venezuela has an internationally high rate of homicide (principally involving young men). Statistics from the Institute of Legal Medicine show a present average of 
about 100 vio lent deaths every w eek. The number of injuries is much higher. Between 1990 and 1999, the annual homicide rate increased in Venezuela from 13 to 25 per 100000 inhabitants. In Caracas, this rate increased from 44 to 81 homicides for every 100000 inhabitants in the same period. Most of these violent events take place during the weekends in the area called ' $G$ reat $C$ aracas' and other urban areas in the country. This represents an enormous drain on health resources, and has a serious psychological impact, notably anxiety disorders and post-traumatic stress disorders. Such psycho logical effects have not been properly quantified. Violent events have important physical and psychological consequences for both the victim and others, and this represents a considerable burden for the health and rehabilitation services.

The overall mortality rate is 4.6 per 1000 inhabitants. Accidents are the third most common cause of death, whereas suicides and ho micides rank seventh. These two categories account for the highest number of years of life potential lost (in Spanish AVPP), mostly among males. The useful years of life lost as a consequence of accidents and violent events are higher or equal to those caused by cancer or cardiovascular diseases, because they mainly affect the infant, juvenile and young adult population.

\section{Non-governmental organisations}

Some non-governmental organisations run ambulatory clinics and there are asso ciations that care for vulnerable groups. These organisations provide their own resources or obtain direct help from the government to carry out their projects, which often involve prevention, treatment and rehabilitation in the area of mental health.

\section{Information systems}

Currently there is a lack of an information system or epidemiological study in mental health. The mental health system narrows its scope by reporting exclusively on mental disorders.

\section{Programmes for particular populations}

The country has specific programmes for the mental health of children and for people affected by natural disasters. There is a $\mathrm{N}$ ational Institute of C hild Psychiatry (Instituto $\mathrm{N}$ acional de Psiquiatría del $\mathrm{N}$ iño) and also a 2-year programme for university-level child and adolescent psychiatry (see above). This is the only specialised programme in the field of mental health in Venezuela.

In Venezuela in 1999 there were massive land slides in Vargas state. A plan for psychological care and rehabilitation was created to care for any victims of future similar tragedies.

\section{Conclusion}

Venezuela has long had adequate health plans and programmes, which have provided immediate responses, sometimes improvised ones, in the area of mental health. The problem has been in their implementation, since priorities have not been properly ascertained, experiences are not taken into account and on-going training and research are not promoted. Venezuela therefore needs to strengthen the implementation of health plans and policies, to meet needs in the area of health, to protect patients' rights, to preserve mental and physical integrity and, consequently, to guarantee the population a good quality of life.

\section{Further reading}

Desjarlais, R., Eisenberg, L., Good, B., et al (eds) (1996) World Mental Health: Problems and Priorities in Low-Income Countries. N ew York: Oxford University Press.

Levav, I., Restrepo, H. \& Guerra de Macedo, C. (1994) The restructuring of psychiatric care in Latin America: a new policy for mental health services. Journal of Public Health and Policy, 15, 71 .

San Juan, A. (2003) Political Violence in Venezuela. Some Preliminary Approaches. Caracas: Centro de Estudios para la Paz, Fundación Centro Gumilla.

World Health O rganization (2001) Atlas. Mental Health Resources in the World 2001. Mental Health Determinants and Populations. Geneva: WHO Department of Mental $\mathrm{H}$ ealth and Substance Dependence.

\title{
Mental health services in Norway
}

\section{Jan Olav Johannessen, ${ }^{1}$ Bjarte Stubhaug ${ }^{2}$ and Jan Skandsen ${ }^{3}$}

\author{
${ }^{1}$ Chief Psychiatrist, Division of Psychiatry, University Hospital of Stavanger, Post Box 1163 Hillevaag, \\ 4095 Stavanger, Norway, email jojo@sir.no \\ ${ }^{2}$ Medical Director, Division of Psychiatry, University Hospital of Bergen, Norway; President of the Norwegian \\ Psychiatric Association \\ ${ }^{3}$ Medical Director, Department of Child and Adolescent Psychiatry, Division of Psychiatry, University Hospital \\ of Stavanger; President of the Norwegian Association for Child and Adolescent Psychiatry
}

ew countries (if any) have experienced the abundance of material welfare $\mathrm{N}$ orway has had for the last decades. The report of the 0 rganisation for Economic Co-operation and Development (OECD) for 2004 places N orway on the very top of the list of 'best countries to live in'. O ne might
Venezuela has an internationally

high rate of homicide (principally involving young men). Statistics from the Institute of Legal Medicine show a present average of about 100 violent deaths every week. The number of injuries is much higher. 